\title{
ANALYSIS OF THE ACCIDENTS AND INCIDENTS OCCURRING DURING THE TRANSPORTATION OF DANGEROUS GOODS BY RAILWAY TRANSPORT
}

\author{
Nijolè Batarlienè, Aldona Jarašūnienè \\ Dept of Transport Management, Vilnius Gediminas Technical University, Vilnius, Lithuania
}

Submitted 23 November 2013; resubmitted 11 February 2014, 17 April 2014; accepted 6 May 2014

\begin{abstract}
The article examines the accidents and incidents taking place while transporting dangerous goods by railway transport. The paper presents and considers research results indicating the way the respondents estimate the main factors related to risk in rail transport. Also, the correlation of the annual losses encountered by enterprises due to accidents and the losses caused by other factors are analysed. The work suggests recommendation measures for reducing accidents in railway transport while shipping dangerous cargoes.
\end{abstract}

Keywords: accidents; dangerous goods; incidents; railway transport; safety; transportation.

\section{Introduction}

Carrying dangerous goods involves the risk of an incident due to the fault of other traffic participants, climatic conditions, badly chosen packaging materials or the lack of marking. Although the transportation of dangerous stuff is always a risky procedure, however, a possibility of managing and reducing risk factors to a minimum is a highly realistic option.

The goal of the article is to analyse the incidents and accidents in the field of transporting dangerous goods by railway transport, to identify key risks related to the transportation of supplies as well as to assess safety aiming at a reduction in the risk of incidents.

Lithuania has not announced prevention measures for shipping dangerous goods. Thus, the problems faced by Lithuania and the EU Member States in transporting such stuff fall into two categories, namely:

- danger posed to the public, infrastructure objects and the environment;

- incidents when oil products and other hazardous substances get into the environment.

This is a frequent phenomenon in the EU Member States, but neither Statistics Lithuania (2013) nor the EuroStat (2013) database provide the exact data on the amount and character of the incidents that take place in the transportation of dangerous goods. Gheorghe et al. (2005) maintains that the complexity of systems plays a major part in risk analyses applied to the transportation of dangerous goods. Detailed calculations take into account the frequency of releasing hazardous substances from the loss of containment accidents and the assessment of consequences by considering the impact of damage mechanisms on the respective land and demographic environments.

As for the transportation of dangerous goods, greater responsibility lies on stuff loading, packing, marking, documentation, acceptance and storage. The risk of an incident occurs in the entire logistic link. Tomasoni et al. (2010) note that, in order to ensure the safety of transportation in choosing vehicles, it is necessary to explore the factors making an influence on transportation risk.

To ensure the safety of the participants involved in the system of dangerous goods, the following factors making an impact on the transportation process should be taken into consideration:

- selection of alternative transport types;

- evaluation of routes;

- evaluation of the technological transportation process;

- assessment of transportation risk;

- possibility of reducing accident risk to a minimum (Blanco 2011).

As the need for hazardous substances increases, the flows of dangerous goods also grow. Having estimated what threat is raised by hazardous substances to the environment, individuals and the whole infrastructure of transport, it is essential to guarantee the safety of these processes. Diernhofer et al. (2010) state that most often 
incidents take place due to mistakes made by persons in production and transportation processes rather than because of the features of hazardous substances.

According to Chakrabarti and Parikh (2011), while shipping hazardous substances, accidents depend on risks. The authors base risk calculations on the incident probability and comprehensive analysis of consequences. The article states that the risk assessment of hazardous substances depends on three factors:

- number of accidents;

- traffic intensity of one day and the density of populated areas;

- length of the route.

Najib et al. (2010) distinguish the importance of information systems to the transportation of dangerous goods, as it is possible to quickly receive the required information on the state of stuff, the location of a vehicle and other necessary information at the right time to the right persons. The related works that evaluate the risk of transporting hazardous cargo is presented by Milazzo et al. (2010), Fabiano et al. (2005) etc.

Tomasoni et al. (2010) described the Transport Integrated Platform (TIP) system used in Italy for shipping dangerous goods. The TIP system has a number of installed functions that may observe the transportation of hazardous substances on the road. The data is collected in real time, the sensors used 'observe' not only the state of a vehicle but also the state of hazardous substances as well as changes in amount, pressure and other physical features. The TIP system may also collect and analyse different data transferred to emergency staff in case of an accident while transporting hazardous substances. The authors also state it is very important to adequately mark the containers of hazardous substances by warning signs, as this is the way to provide the receiver with all the required information on which hazardous substance has been delivered.

Bouissou et al. (2011) explained the QRA system applied in France. The main goal of the system is risk assessment while transporting DC by road. The system can simultaneously assess the consequences and different possible probabilities of incidents.

Kawprasert and Barkan (2008) predicates that the main task is to identify opportunities to reduce risk by considering critical factors associated with each possible route while simultaneously taking into account the production and consumption levels at each location of the network. The authors present a risk analysis model combined with an optimization technique to formally consider a reduction in risk by means of making the rail route structure of transporting hazardous materials more rational.

\section{Carriage of Dangerous Goods by Lithuanian Railways}

Prior to analysing the accidents occurring in railway transport, the share represented by dangerous stuff in the total amount of goods transported by rail in Lithuania should be established (Fig. 1).

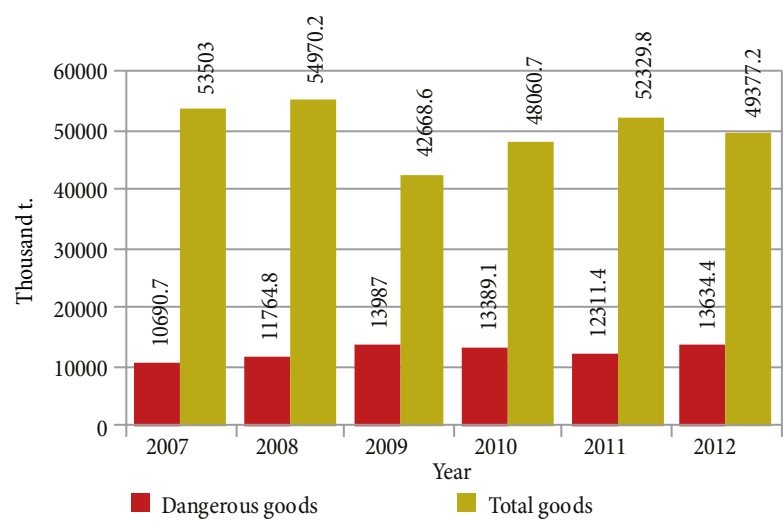

Fig. 1. A comparison of the number of dangerous goods with the total number of goods (Statistics Lithuania 2013)

The below diagram demonstrates that dangerous goods make up about the one third of the total supplies transported by rail. Although the number of all goods fell insignificantly, however, the number of dangerous stuff, except for the year 2011, was gradually increasing; if compared the year 2012 with the year 2007, it grew by about $22 \%$. The largest part of dangerous goods is carried by transit.

\section{Incidents on Lithuanian Railways}

Incidents on railways are divided into four groups:

- a derailment is an incident when, due to a collision of trains and rolling-stock or a train and railway vehicle derailment, the collision of trains and rolling-stock with road transport or other means of transport, one or more persons lose their lives, or five or more persons are injured, or damage amounting to at least 2 million EUR is done to railway infrastructure, rolling-stock, environment or the property of legal persons; a derailment is also any other similar incident because of which it is impossible to control and (or) manage traffic safety on railways;

- an accident is an incident of railway transport when trains and rolling-stock collide, trains collide with rolling-stock, buildings, installations or rolling-stock derails; railway transport accident may occur in the crossing, and due to moving rolling-stock, more than four persons are injured and fire breaks out in railway transport.

- the major accident is the one that involves at least one moving rolling-stock and at least one person lost his/her life or was heavily injured or great damage was done to rolling-stock, railing, other installations or environment or traffic was cancelled for a long time. Great damage is considered to be EUR 150000 or more. This definition does not include accidents in workshops, storehouses and depots.

- a break is an incident that occurred due to the exploitation of rolling-stock and trains, had a negative impact on control over traffic safety and management during exploitation, but did not cause derailment and accident consequences. 
According to the data provided by Statistics Lithuania (Fig. 2), the number of railway incidents as of the year 2006 has been decreasing annually. If compared the year 2012 to the year 2004, the number of accidents decreased by about $33 \%$.

Fig. 3. displays the number of accidents and breaks in railway transport that involves freight trains carrying dangerous goods.

As shown in Fig. 3, the number of accidents is insignificantly increasing. In the year 2012, the number of accidents increased in particular and exceeded the sum of the years 2008-2011. However, over this period of time, there was no serious impact on the environment and population, as the majority of accidents happened due to the violation of rules on traffic safety by strangers. The last major accident took place in August 2006, when the train carried petrol from the company Mažeikiu nafta to fuel terminal Ave-Matrox located in Gaižiūnai, near Achema factory. The train derailed while petrol in containers exploded and a great fire started. There was no threat to human health; however, damage done to the environment was great. According to experts, the accident took place due to a breakdown in railing construction. The railings could break due to mounting mistakes, an improper junction, etc. The number of breaks was the largest in the year 2009, whereas in the following years 2010 and 2011, they were completely avoided.

There were no derailments this year. A single major derailment happened in Lithuania on 4 April 1975

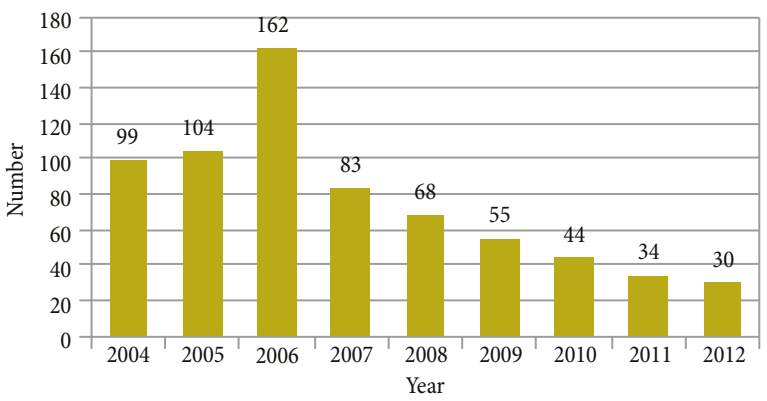

Fig. 2. The number of incidents in railway transport (Statistics Lithuania 2013)

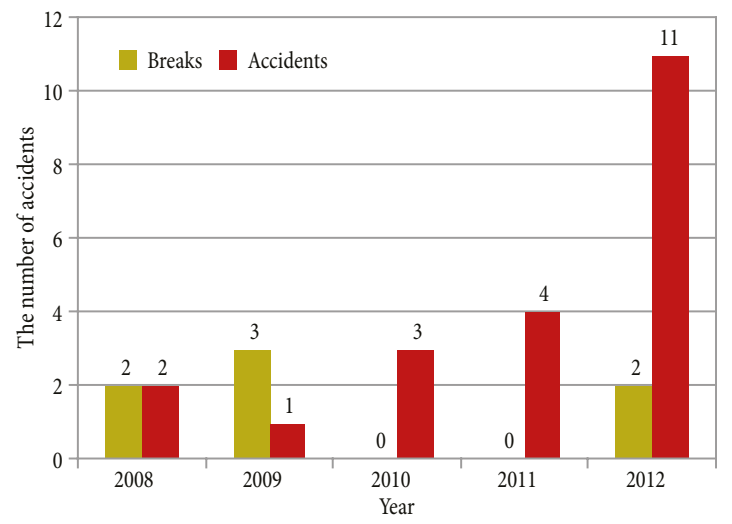

Fig. 3. The number of accidents and breaks while carrying dangerous goods (EuroStat 2014) beside the railway station in Žasliai. Apart from 20 persons died and 80 injured, great damage was done to the environment.

Although with reference to statistical data the number of accidents is decreasing, nevertheless, it still remains large, which enhances risk not to avoid the major accidents. Having analysed the incident rate, it is possible to make a conclusion that the major part of them happen in railway crossings and passages due to the fault of drivers and pedestrians who violate requirements for road traffic regulations. The most important rule of safe traffic in crossings is often simply forgotten - the train has the right-of-way in respect of other means of transport and pedestrians. According to data provided by Lithuanian Railways (Fig. 4), 82\% of the incidents happen ignoring the above introduced rule.

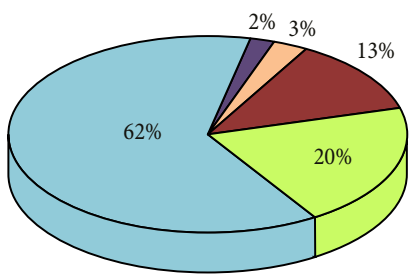

Train collisions, including collisions with obstacles without breaking their clearances Rolling-stock derailment

Traffic incidents in rail crossings

$\square$ Traffic incidents during which due to moving rolling-stock people suffered

Fires on rolling-stocks

Fig. 4. Traffic incidents in railway transport in 2004-2012 (EuroStat 2014)

While analysing the period 2008-2012, no threat was posed to goods during the occurred incidents; however, the car that goes untimely might cause train derailment while the consequences of that would be great. Due to the irresponsible work of the staff and non-conformance with the rules, about $15 \%$ of accidents take place.

\section{Research Results}

To process the information received from expert surveys, a comparative analysis of the researched data was used while the sizes are expressed in per cent in order the data would be compared. The averages of data and the correlation of factors were calculated.

Five factors were provided for the survey and had to be evaluated referring to the 5-point system based on their importance. The summarised respondents' answers, the averages of their evaluation and standard deviations of the answers are provided in Table.

According to the respondents, the greatest risks are related to the features of hazardous substances, i.e. the impact on the environment and human being, while loading and unloading (average evaluation - 3.79) in particular, the risk of fire and explosion (3.4) as well as the speed of transporting goods and developing driver competences (3.33). These three factors should be given 
special attention. Although the evaluation of the conformance of containers and vans with the requirements of regulations concerning the international carriage of dangerous goods by rail (RID) is less than 3 points, however, in order to ensure the proper security of goods, these two factors must be also assessed. The averages of the evaluated all five factors are graphically shown in Fig. 5.

The analysis of the losses incurred by enterprises is based on the respondents' answers to the questions about the losses incurred by enterprises due to the accidents caused by transporting dangerous goods as well as a result of other factors.

The analysed data are presented in Fig. 6.

The examined statistics presented in Fig. 6 reveals that the losses incurred due to accidents and the losses affected by other factors distribute in a very similar way. Smaller than LTL 10 thousand losses due to accidents rather than considering other reasons are incurred by an increase in $10 \%$ of the respondents. The frequency of losses counting LTL 10-50 thousand and LTL 50-100 thousand due to accidents and losses caused by other factors is practically the same. Larger than LTL 200 thousand losses caused by accidents rather than by other reasons are incurred by a decrease in $4 \%$ of the respondents, and LTL 100-200 thousand due to accidents are incurred by a decrease in $9 \%$ of the surveyed participants.

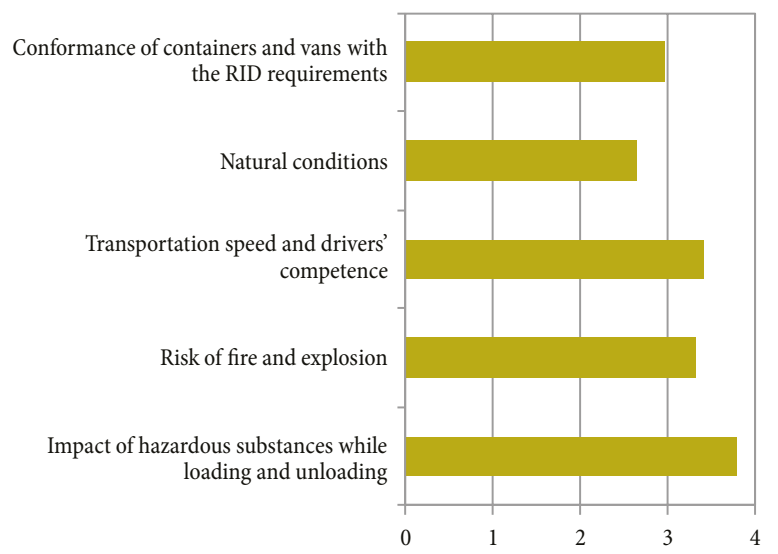

Fig. 5. The averages of risk factor evaluation (source: authors' calculations)
On the basis of the above responses, it is possible to state that, in order to reduce the losses incurred by the enterprise, attention to accident prevention (Thomson 1999) and a reduction in losses should be distributed proportionally to attention to other circumstances (proper planning, containers and vans meeting requirements, proper packages).

The analysis of the accidents that occurred while shipping dangerous goods has disclosed that accidents or incidents in the field of transporting dangerous cargoes cause more problems than the transportation of usual stuff. The problems of the transportation of dangerous goods are important not only to the enterprises engaged in shipping dangerous stuff, but also to all institutions responsible for taking control over dangerous goods for the transportation of which, risk and possible danger to the safety of the public and environment are inevitable.

In order to ensure the safe process of transporting dangerous goods, different controlling institutions responsible for the safe transportation of such stuff should be combined. Necessary measures that must be taken to ensure the completely safe transportation process are as follows:

- control on the road;

- speed limits to the vehicles transporting dangerous goods;

- mechanisms for controlling traffic flow;

- safety measures in crossings;

- improved infrastructure.

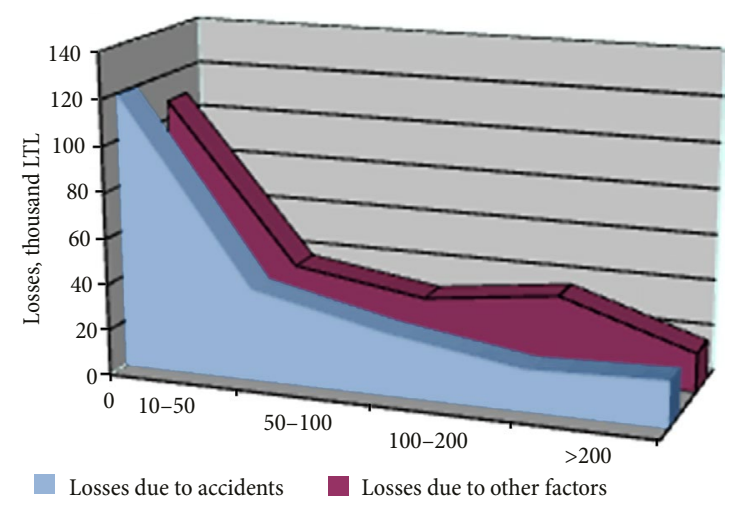

Fig. 6. Annual losses incurred by enterprises, thousand LTL (source: authors' calculations)

Table. The evaluation of the factors indicated by the respondents

\begin{tabular}{lccccccc}
\hline \multicolumn{1}{c}{ Evaluation/Factor } & $\begin{array}{c}\text { Very } \\
\text { important }\end{array}$ & Important & $\begin{array}{c}\text { Moderately } \\
\text { important }\end{array}$ & Unimportant & $\begin{array}{c}\text { Completely } \\
\text { unimportant }\end{array}$ & $\begin{array}{c}\text { Evaluation } \\
\text { average }\end{array}$ & $\begin{array}{c}\text { Standard } \\
\text { deviation }\end{array}$ \\
\hline $\begin{array}{l}\text { Impact of hazardous substances } \\
\text { while loading and unloading }\end{array}$ & 65 & 53 & 33 & 25 & 7 & 3.79 & 1.18 \\
\hline Risk of fire and explosion & 39 & 57 & 44 & 25 & 18 & 3.40 & 1.24 \\
\hline $\begin{array}{l}\text { Speed of transportation of } \\
\text { dangerous goods and drivers } \\
\text { competence }\end{array}$ & 37 & 28 & 84 & 26 & 11 & 3.33 & 1.09 \\
\hline $\begin{array}{l}\text { Natural conditions } \\
\begin{array}{l}\text { Conformance of containers and } \\
\text { vans with the RID requirements }\end{array}\end{array}$ & 25 & 29 & 38 & 37 & 54 & 2.64 & 1.40 \\
\hline
\end{tabular}




\section{Recommendation Measures for Reducing the Accident Rate}

The European safety and health policy covers the risk assessment and implementation of prevention measures by giving priority to risk elimination regarding the source of its occurrence. These principles should be also applied for implementing the safety plan covering rail vehicles and equipment, activity planning and personnel. The recommendation includes making a record of accidents that may be analysed as an integral part of risk assessment contributing to the identification of what actions should be best taken.

The number of the accidents taking place in rail transport must be reduced with reference to:

- reducing the amount of dangerous goods for one transportation unit, as a smaller amount decreases the risk of threat to the public and environment;

- ensuring the quality of loading, container, mounting, transporting and unloading;

- giving attention to climatic conditions and avoiding bad weather that may include a poor visibility level;

- ensuring the preparation, experience and knowledge of the train driver and other participants related to transportation while transporting dangerous goods;

- implementing prevention measures, at the time of which attention should be paid to the technical state of vans thus ensuring the tightness of containers and marking;

- taking preventive actions in rail crossings where drivers and pedestrians should be informed about the situation of the accident rate in railway crossings and encouraged to follow the provisions of road traffic rules;

- considering the incidents that have already taken place and introducing all possible measures to avoid similar situations;

- installing new technologies.

To insure the safety of transporting dangerous goods and selecting appropriate means, it is necessary to investigate the factors having an influence on the danger of transportation. Organizing the shipment of dangerous stuff by rail transport, it is required to consider the following factors:

- progressive technology of the transportation process;

- interaction with other methods of shipping;

- requirements for technical means;

- requirements for the construction, equipment and type approval of tank-wagons;

- inspection and marking;

- transportation control;

- elimination of accident results,

- special marking provisions for environmentally dangerous substances.

All above introduced factors depend on informational supply.

\section{Methodology for Solving Problems}

An analytical solution to the approached problems is complicated due to the formalization of the processes covering the transportation of dangerous goods. Conducting experimental researches requires plenty of time and finance, or practically are not solvable issues. Therefore, it is advisable to use mathematical modelling methods for the processes of shipping dangerous stuff. The created models can be the basis of scientifically grounded methodology that allows:

- estimating exploitation parameters that affect the probability of incidents and accidents as well as complying with regulations that can diminish such probability;

- offering typical prophylactic means and estimating their effectiveness;

- evaluating the probability of accidents that may happen considering the category of supplies.

The suggested improvements to the methodology estimating the probability of railway accidents should be used for establishing all optimal parameters for the elements of the transportation process and the safest route for delivering dangerous goods.

The methodology created according to statistical models includes a pattern of a railway accident that is the most important part because it allows estimating the probability of incidence appearance. For practically proceeding with the estimation of the probability of railway accidents, it is necessary to assess and classify the parameters affecting the probability of railway accidents. Conditionally, the presented parameters fall into six groups:

- parameters of dangerous goods, including the type of the good indicating dangerous properties; the physical state of the cargo;

- exploitation parameters of vehicles, the means of loading mechanisms like unloading operations, containers and packages, equipment for good storage; technical means of transport such as mechanisms for loading-unloading operations, containers and packages, parameters of equipment for good storage (possible load, capacity, obstruction of dust and damp, etc.); the use of other equipment;

- technological parameters, including the distances of transportation, the time of the day, the frequency of unloading, conditions for storage, composite loading with other dangerous and not dangerous goods;

- parameters of rail traffic such as the speed of traffic, special transportation service, the specialization and signs of danger;

- parameters that characterize train drivers and operational personnel: professional classification, the state of health, experience of working with dangerous goods, special training;

- parameters that define the surrounding environment: climate conditions, meteorology, a character of the route. 
The transportation of effective and safe dangerous goods is possible only by a good provision of information.

Every two years, computer variants on the international transportation of dangerous supplies by railways (RID) are prepared. Also, regulation requirements for shipping dangerous goods by international roads are fitted for transportation inside the country. Requirements for control over carrying dangerous stuff are prepared for inspectors, according to the EU directives and other instructions. This work enables to improve the transportation process and to create the information system as well as describes the necessity of creating methodological basics for the safer and more perfect transportation of dangerous goods.

\section{Conclusions}

Shipping dangerous goods is one of the most complex and extra safety requiring transportation technologies. Therefore, because of specificity and risk, this process must be precisely controlled, regulated and handled.

The carried out analysis of the accidents and incidents taken place in rail transport offers a possibility of making a conclusion that, although the number of the whole accidents decreases, dangerous stuff can be often observed in the occurring accidents or incidents. Non-conformance with road traffic rules by strangers and other vehicles, which poses great risk not only to them but also to people around, has become the main reason. Within the year under research, great accidents have been avoided; however, there is no guarantee that a similar situation will remain in the future.

With reference to data on the research conducted by the author, losses due to accidents and regarding other factors distribute in a very similar way. Enterprises should pay equal attention to mounting goods (prevention of the losses incurred during accidents) and measures that help with preventing accidents as well as to procedures contributing to a reduction in accident consequences.

The incurred losses could be reduced by the complex use of different measures only, as individual actions merely reduce the probability of the occurrence of specific risk, whereas the sum of the adequately chosen measures allows a reduction in risk level to a tolerable limit.

The conducted research has revealed it is necessary to apply prevention measures and inform all traffic participants about the danger of shipping dangerous goods. The staff aware of that would try to keep a safer distance and adequately assess the risk of danger. This could reduce the number of accidents and incidents in railway transport.

\section{References}

Blanco, A. M. 2011. Safety adviser for the transport of dangerous goods by road, Seguridad y Medio Ambiente 31(123): 1-8. Available from Internet: http://www.mapfre.com/fundacion/html/revistas/seguridad/n123/articulo4En.html
Bouissou, C.; Ruffin, E.; Defert, R.; Prats, F.; Dannin, E. 2011. A new QRA model for rail transportation of hazardous goods, in Proceedings of the 11th International Symposium on Loss Prevention and Safety Promotion, 31 May-3 June 2004, Praha, Czech Republic, 4283-4289.

Chakrabarti, U. K.; Parikh, J. K. 2011. Route evaluation for hazmat transportation based on total risk - a case of Indian state highways, Journal of Loss Prevention in the Process Industries 24(5): 524-530. http://dx.doi.org/10.1016/j.jlp.2011.03.002

Diernhofer, F.; Kohl, B.; Hörhan, R. 2010. New Austrian guideline for the transport of dangerous goods through road tunnels, in 5th International Conference 'Tunnel Safety and Ventilation' 2010, 3-4 May 2010, Graz, Austria, 44-51.

Fabiano, B.; Currò, F.; Reverberi, A. P.; Pastorino, R. 2005. Dangerous good transportation by road: from risk analysis to emergency planning, Journal of Loss Prevention in the Process Industries 18(4-6): 403-413. http://dx.doi.org/10.1016/j.jlp.2005.06.031

EuroStat. 2014. Transport Accident Statistics. European Commission. Available from Internet: http://epp.eurostat. ec.europa.eu/statistics_explained/index.php/Transport_accident_statistics

EuroStat. 2013. Basic Figures on the EU: Summer 2013 Edition. EuroStat Compact Guides. 6 p. Available from Internet: http://epp.eurostat.ec.europa.eu/cache/ITY_OFFPUB/KSGL-13-002/EN/KS-GL-13-002-EN.PDF

Gheorghe, A. V.; Birchmeier, J.; Vamanu, D.; Papazoglou, I.; Kröger, W. 2005. Comprehensive risk assessment for rail transportation of dangerous goods: a validated platform for decision support, Reliability Engineering \& System Safety 88(3): 247-272 p. http://dx.doi.org/10.1016/j.ress.2004.07.017

Kawprasert, A.; Barkan, C. P. L. 2008. Effects of route rationalization on hazardous materials transportation risk, Transportation Research Record 2043: 65-72 p. http://dx.doi.org/10.3141/2043-08

Milazzo, M. F.; Lisi, R.; Maschio, G.; Antonioni, G.; Spadoni, G. 2010. A study of land transport of dangerous substances in Eastern Sicily, Journal of Loss Prevention in the Process Industries 23(3): 393-403. http://dx.doi.org/10.1016/j.jlp.2010.01.007

Najib, M.; Boukachour, H.; Boukachour, J., Fazziki, A. E. 2010. Multi-agent framework for hazardous goods transport risk management, International Journal of Information Science and Management (Special Issue 2): 27-34.

Statistics Lithuania. 2013. Available from Internet: http://www. stat.gov.lt/en

Thomson, B. J. 1999. International co-operation in hazardous materials accident prevention, Journal of Loss Prevention in the Process Industries 12(3): 217-225. http://dx.doi.org/10.1016/S0950-4230(98)00052-7

Tomasoni, A. M.; Garbolino, E.; Rovatti, M.; Sacile, R. 2010. Risk evaluation of real-time accident scenarios in the transport of hazardous material on road, Management of Environmental Quality 21(5): 695-711. http://dx.doi.org/10.1108/14777831011067962 